\title{
Relationship between personality disorders and relapses among sample of substance abuse patients
}

\begin{abstract}
This study aimed to examine the relationship between Personality Disorders and Relapses among Sample of 75 Substance Abuse Patients (personality disorder scale (prepared by the researchers) were used Pearson Correlation Coefficient showed that there are statistically significant relationship between Antisocial personality disorder(ASPD), Borderline personality disorder (BPD, Avoidant personality disorder (AVPD) and Dependent personality disorder (DPD) and substance abuse relapses $(\mathrm{P} \leq=0.00)$. Also the result showed that there are no statistically significant relationship between Paranoid personality disorder(PDD), Schizoid personality disorder(SPD), Schizotypal personality disorder (STPD), Histrionic personality disorder(HPD), Narsistic personality disorder(NPD) and Obsessive-Compulsive personality disorder (OCPD), The Regression and Prediction Coefficient (stepwise) was also used and showed that the Dependent personality disorder, Borderline personality disorder and Antisocial personality disorder predicts substance abuse relapses.
\end{abstract}

Keywords: personality disorders, substance abuse, relapses
Volume 6 Issue 6 - 2016

\author{
Osama Hasan Gaber, Mohamed Elsaed \\ Abelfatah
}

Department of Psychology, Najran University, Saudi Arabia

Correspondence: Osama Hasan Gaber, Department of Psychology, Najran University, Saudi Arabia, Tel 009-665-613803-47,Email dr.osamagaber@yahoo.com

Received: October 06, 2016 | Published: November 18, 2016

\section{Introduction}

The problem of substance abuse relapses is considered as complicated international problem, where there are over lap of several social, political and cultural factors, economic, financial, security, and other factors. Narcotics also are a main problem occur within the individual; in his mind, thoughts, beliefs, judgments and estimates, and honorable feelings and emotions and temperament, and behavior also, any attempt to limit this problem cannot achieve its goal only by focusing on what is happening inside the individual. Every failure wished his anti-drug plans may be the basis of lack of awareness of the importance of what is happening within the individual, or the lack of knowledge of the appropriate method to create the desired change or the palm of unwanted change. The psychological side axis represents the foundation for all the effort, as the best man is the final outcome intended by all scientific effort. Substance abuse causes chronic physical, psychological and acute social effects in varying amounts along with serious social problems in the form of crime, unemployment, family dysfunction and disproportionate use of medical care. Science has not yet fully explained the physiological and psychological processes leading to drug abuse. Substance abuse affects above 50million people worldwide. Abuse of legally prescribed drugs is also increasing alarmingly. The annual worldwide drug revenues are now close to arms trade. ${ }^{1}$

The researchers believe that the trends and internal convictions outs for substance abuse is not an easy process and is not built, composition and development by through programs and plans studied possibilities to do so are available to them, and perhaps the important issues in operations to deal with the issue of abuse and addiction to substances can be called a case of relapse, Relapses is the return of certified the substance (addicted) to the use of these materials, after his success in dropping out of use for a limited period. Addict stop substance use for a variety of reasons to undergo treatment or be forced to leave as a result of external circumstances, such as moving to a new environment where the drugs are not available. Where it was noted that those who are forced to leave the substance are more likely to relapse than those who drop out of conviction, also it noted that those who are undergoing treatment are less likely to relapse than those who leave the drug without medical assistance. It decreases with the increasing likelihood of relapse time. Whatever the reason for stopping the use of substance abuse, the person remains vulnerable to a relapse.

From the treatment perspective, relapse and recovery are key issues. The high rate of relapse is an especially frustrating problem, and the notion of a "cure" remains elusive. Substance abuse careers are episodic, with periods of abstinence, reduction of use, and relapse the prevailing pattern, often with the course of events being influenced by external factors such as availability of drugs and societal pressures. Given the patterns of relapse and remission, a variety of interpretations of the nature of substance abuse as a disease condition, how it should be treated, and what the goals of treatment should be, have evolved. ${ }^{2}$ Relapse is defined as the return to abusing a substance regularly and sometimes uncontrollably. This differs from a lapse, which is considered a one-time slide into substance abuse and doesn't occur more than once. On average, between 25 and 50 percent of substance abusers will return to use drugs or alcohol within two years of receiving treatment. ${ }^{3}$ Also Many studies have been performed highlighting that abstinence, or refraining from using the substance at all, is the only true way to prevent relapse. Addicts who remain abstinent for five years or more only have a 15 percent chance of relapsing while those sober for a year have a little more than a 50 percent chance. One-third of addicts who abstain for less than a year will maintain their sobriety. ${ }^{4}$

Psychotherapists, drug abuse counselors, treatment, program planners, and researchers have theories about what relapse is, why it occurs, and how it is prevented. Such theories are important because they shape the treatments provided to drug abusers. For example, a therapist who believes that drug abuse is a chronic, relapsing disease will treat a patient who has relapsed differently from one who views drug abuse as a secondary symptom of underlying psychopathology. A clinical researcher who accepts a theory of inherited endorphin deficiency will design and test treatments for relapse differently from a researcher who believes that drug abuse is learned behavior. ${ }^{2}$ Because people who suffer from dual disorders are more likely to relapse of substance abuse, research and clinical intervention should focus on 
the goal of relapse prevention. ${ }^{5}$ According to researchers believes the mental health related to substance abuse relapses, this is the main goal of the current study, examine the relationship between personality disorders and substance abuse relapse. Researchers believe that some personality disorders that could lead to relapse of substance and addiction, due this because of that individual's character is more likely here for the dissolution of drug abuse, or because these personal find in substance a way to change and modify the mental state which leads to substance abuse to also Personal injecting drugs has a set of attributes, regardless of whether these qualities cause or result includes traits aggressiveness, impulsivity, Psychopathic and low self-esteem and depression, and introversion. Also Substance abuse, as due to the personal structure of the individual, as there are more troubled characters tend to addiction, which is therefore not to offer the general consensus of the character, as is the way that expresses their personal discomfiture for.

According to numerous studies have been carried out to determine the link between those who abuse drugs and alcohol and those who have personality disorders. The majority of data collected points towards a direct correlation between the two. Depending on the individuals study, there is a $50 \%$ to $75 \%$ chance that a drug or alcohol addict will also suffer from one or more personality disorders. Most of the traits associated with these afflictions can be spotted while an individual is an adolescent. However, it may be difficult to differentiate between typical adolescent behavior and the common mental symptoms linked to these disorders. The researchers believe that the problem facing researchers is that much of the evidence on the existence of a relationship between personality disorders and substance abuse relapses are derived from substance abuse samples. Are personality disorders due to substance abuse relapses? Or vice versa, or are they just accompanying it? The correlation studies do not reveal causal relationships, even if they are strong and frequent that relationship. The best way to detect the relationship between the role of personality disorders in substance abuse relapses can be by predictive Studies, especially in the absence of the ability to use the experimental approach to such cases in accordance with the rules prohibited the use of samples in scientific studies.

\section{Objective}

Considering the background above, this research aimed to:

i. Examine the relationship between personality disorders and relapses among a sample of substance abuse patients,

ii. Examine the predictive relationship for relapses through personality disorders.

\section{Literature review}

\section{Substance abuse}

The problem of substance abuse is considered a threat to a lot of people in the communities, especially the youth, but the danger has increased to the point of using it as a weapon hidden in wars between nations, targeting in particular young people category in order to turn them from a national force effective and productive to the destructive force cripple the movement of that society and dissipates wealth. ${ }^{6}$ It can be defined substance abuse as a person accustomed to a particular drug, so get used to his body cells in this narcotic substance. And if they were to stop the drug suddenly led to the emergence of physical and psychological changes, which pushes the individual to search to look for these narcotic substances at all costs it. There are those who consider that the substance abuse case of psychological and sometimes physical state caused by the interaction between the individual, the substance abuse and behavioral responses characterized by always contain a forced feeling to occur psychological impact. ${ }^{7}$ A lot of theories have attempted to explain the phenomenon of substance abuse, for example, biological theory owners of this trend believe that addiction is only a genetic disease with a genetic basis, and concluded that the results of the studies done on identical twins and similar, the study of the children of alcoholic and drug addicts, and despite the results, but the studies carried out on the children of the families of drug addicts in both north of America and Western Europe, have shown that children who belong to parents addicted to alcohol addiction is common among them, as the children who are descended from parents addicted to alcohol increases the prevalence rate among them at about four times the children who are descended from parents is not addicted rate. The biological explanation is the step complementary research conducted in the field of genetics and addictive behavior, biological Changes have stand out to clarify how they are by these genetics. Has interpreted the static receptors theory, one of the biological theories unexplained phenomenon of addiction, where the owners of this theory believe there are two types of receptors in the nerve cells, the first type is the one who is doing its job and interacts with the drug user, and the second type, resident does not react, and when one continues to the abuse of the drug the drug, the receptors static active and become one of the first type the future, causing an urgent need to address the increasing amounts of the drug the drug, and this is called the phenomenon of endurance, on the other hand, if one refrained from taking the drug addicted to it, it would cause a significant activity in excess activated receptors in the nerve cell, which was static, talk phenomena and withdrawal symptoms, which vary depending on severity of the drug user; and those symptoms usually continue until they return to the receptors that activated the drug because of drug intake to the status of natural sleep. ${ }^{8}$ The researchers believe that it is not logical that in accordance with the biological theory is judged that there is a rule of thumb about that addiction is his inheritance and because it is not at all assignments parents of addicts have children addict because, if you were to admit it. In this case, we cancel the effect of the environment in the formation of consciousness the experience may be parents lived in conditions and suffered from psychological pressure has led them to addiction and this does not mean that it will be with the children. The circumstances lead them to live in a different environment from the one where the parents lived.

But early psychodynamic studies of drug abuse, however, ignored social and even familial factors and viewed the abuser in a psychodynamic vacuum. All types of drug craving were seen as 195 representing a single disease characterized as an impulse disorder in which the "ego is subjugated" by an "archaic need for oral gratification". "Also the theory of psychoanalysis explain the dependence on substance abuse in light of the oppression and in light of the disturbances that occur in early childhood, include these disorders gratification organic operations in compassion is the axiom oral and practical sexual development stage oral even penis stage and which breaks down the ego and show the maturity fears such as fear of lack of saturation and the fear of castration attendant feelings of guilt. In addition to a disorder of love relationships between the addict and the father and mother, the emergence of bilateral emotions, and the theme of love turned to the subject of the original drug. ${ }^{10}$ Also, psychoanalysts find that addiction is a relapses to childhood, the pleasure principle, and theories of analytical contemporary rely on the theory of relations, which explain the addictive response to subsequent failure in the construction of the self and the mechanism of adaptive, and this is seen as an attempt by the individual to eliminate 
the deficiencies in personal since childhood, and interactions troubled with the parents of the early stages of life, as psychoanalytic theory assumes that addiction is an attempt Resume for telemedicine self it is a modern analytic currents, and is a pioneer of this trend, addiction for him not just to escape from problems, or the desire for a sense of activity or self-destruction, Substance in this case is the kind of self-medication to get rid of psychological problems, and emotional pain. In spite of these efforts of self-therapy, but it is doomed to failure because of the problems and complexities of non-stationary patterns of abuse. ${ }^{8}$

On this subject, the researchers believe the failure of psychoanalytic theory to explain the phenomenon of addiction. Not all addicted people is an attempt to relapses to childhood or is the explanation for the problem of installing oral stage also claimed that psychoanalytic theory scientists, this is masking the role of an environmental and cultural factors in addictive as that may be one of the reasons addictive need to prove oneself and the need for security or because of internal conflicts, which suffers from a person. But the behavioral theory explains addiction, it usually reflex reaction and any kind of reward subsidized associated with a property. The positive reinforcement is able to create the powerful habit of a craving for the drug, and the habit becomes a recurring pattern of behavior which is difficult to change. ${ }^{11}$ The researchers believe that behavioral theory have overlooked the role of internal psychological factors and the impact of the mental health of the addicted person. Not all addictive behavior is through the learning process, and therefore if we accept this logic, then we must ask ourselves about the role of the mental health, the role of internal conflicts and the role of personality disorders in substance abuse process?

The psychological and social theory explains addiction in light of what is provided to the addict of the fun and improve social interaction, and to satisfy the need for a sense of power, and the temporary revocation of the effect of pressure and forget painful memories. ${ }^{12}$ According to social learning theory, our observations of other people engaging in addictive behavior can lead to the development of addiction. When we observe the behaviors and reactions of other people using addictive substances (or activities) we may wish to repeat what we saw. For instance, suppose we observed an agitated, frazzled parent coming home from work. She drinks a few drinks, then becomes relaxed and fun to be around. We observed that alcohol is a good way of coping with stress. ${ }^{13}$ According to DSM-5 no separation between the diagnosis of dependence and substance abuse as in DSM-IV. Rather, criteria are provided for substance use disorder, accompanied by criteria for intoxication, withdrawal, substance/ medication-induced disorders, and unspecified substance-induced disorders, where relevant. The DSM-5 substance use disorder criteria are nearly identical to the DSM-IV substance abuse and dependence criteria combined into a single list, with two exceptions. The DSMIV recurrent legal problems criterion for substance abuse has been deleted from DSM-5, and a new criterion, craving or a strong desire or urge to use a substance, has been added. In addition, the minimum was diagnosed with substance abuse in DSM- 5 with two or more of the criteria in contrast to the diagnosis of substance abuse in DSM-IV accordance with the standard or more only set. ${ }^{14}$

\section{Relapses}

Many people believe that the relapses are that the person stalled deal for a period of time the drug abuse again, this is not quite true. Should be fully aware that there is a big difference and vastly between stopping the abuse and the recovery, as the stop means that a person abstention from dealing accidently or came this stop without proper basis and therefore this stop often be doomed to failure and that the natural and inevitable result We are back again to deal again. But The recovery shall stop deliberate was based on a study came under the supervision of persons or entities who have experience in the field of recovery, and stop in this case is a very important step, but the stop is not a goal in itself but followed several steps enables an addict to maintain this setup. The benefit is also that the person in recovery addict finds a complete change in all the affairs of his life to the best of his life and be well thought out and are able to communicate with the community again. We always say what is the use if the recovery did not create the addict a new life with all its sense of the word. And therefore it can be defined as a relapse Recuperating addict return to the old way of life (the life of the behavior of engagement) and the life of the addict begins to deteriorate again and call this (intellectual relapses).

The researchers believe that the relapse process is one of the most important phenomena among individuals addicted to substance abuse. And the most important thing in the relapses phenomenon is to understand what is the role of psychological factors that lead to their relapses. As relapses vary depending on personal style, but there are common factors among the most important of relapsing back into substance abuse as well that the tension, fear and frustration as the most important thing for people addicted to substance abuse is old friends but all are secondary reasons for either the real reason for the relapses is mental health and willpower for the substance abusers. Also substance abuse relapses constitutes for a major obstacle in the treatment of behavioral addiction operations. prevent relapses is the first o conditions for any attempt to bring about positive changes and the successful long-term behavior of addicts. ${ }^{15}$

So what is the psychological reason for the setback after the addict stop using the substance? we need more research to prevent addicts from relapse, especially after stopping the addictive process. According to ${ }^{16}$ The addictions field has long used the term relapse to describe a return to drinking or drug use following a period of voluntary abstinence by those who have a history of AOD (Alcohol and other Drug) related problems. The field has more recently attempted to distinguish lapse or slip (a brief episode of AOD use) from relapse (the resumption of more extended and excessive AOD use involving the return of symptoms meeting diagnostic criteria for a substance use disorder). Rates of lapse and relapse are difficult to compare across studies due to different definitions of these terms. According to ${ }^{15}$ defined the relapse as a setback that occurs during the behavior change process, such that progress toward the initiation or maintenance of a behavior change goal (e.g., abstinence from drug use) is interrupted by a reversion to the target behavior. We also take the perspective that relapse is best conceptualized as a dynamic, ongoing process rather than a discrete or terminal event.

As for the differences between relapse rate among adults and adolescents have different patterns of relapses among adolescents and adults. Where cases are related to relapse in adults for those who suffer from anger, frustration and social pressures or conflicts between people. Either cases related relapse in adolescents in cases where the relationship with direct social pressure or indirect also linked to the diagnosis of personality disorders setback in cases of adults and adolescents. ${ }^{17}$ Substance abuse relapses occur for several stages in the first stage of intellectual relapse and where the person feels recuperating strong desire to return to the substance abuse. After that the degree held less than what has in the forced feeling anticipating a lot of time and who feels the inability survive without substance abuse. Then the last stage, a return to substance abuse..$^{18}$ Therefore, the researchers believe that the most important goal in the treatment 
programs for substance abuse patients concentrated on relapse preventing operations because of its impact on the deterioration of the treatment plan for substance abuse patients.

Relapses Interpretation according to a genetic theory has also been proposed for opiate dependence. Goldstein (1978) hypothesized that some individuals might be predisposed to develop narcotic dependency. He hypothesizes that a person could inherit an endorphin deficiency. If people with the deficiency happened to use narcotics, they would discover a "normalizing" or euphorigenic effect in excess of that experienced by people without the abnormality. This effect would predispose them to dependency opiates and make it harder to remain abstinent. Social learning theory models in a relapse for addiction focused on the role of the classical and parental conditioning. However, it focuses on cognitive processes in maintenance and modification behavior. The various social learning theories complement conditioning theory by focusing on the cognitive processes occurring between stimulus and behavior. Relapses model of substance abuse within the framework of social learning theory is based on three key elements. First, the patient is facing great pressure by refraining from substance abuse and secondly the suffering of the patient's expectations about who can live without the use of narcotic substances and the third a lack of possession of a patient behavior and skills in the face of the conflict between living without substance dependence or narcotic substances. While those interested in studying the dynamics of behavior finds that addiction or relapse of addiction is a symptom of mental disorders such as personality disorders or emotional disorders . Some chemically dependent patients do, however, have severe psychopathology which predates their drug use; and the psychopathology will persist, or become more overt, after sustained abstinence from drugs. Referred to as dual diagnosis (a major psychiatric disorder not caused by drug abuse combined with a substance abuse disorder), such patients are difficult to treat in traditional substance abuse treatment programs and often do not do well with psychotherapy or other modes of psychiatric treatment. Many bounce back and forth between drug treatment programs and mental health clinics or hospitals, generally creating havoc in both. ${ }^{2}$

In general, there are directions on the personal role in addiction. The first is the relationship between personality disorders and addictive as numerous studies have shown that the antisocial and borderline personality disorders related to addiction. In the second, the personality traits most often found to be related to excessive substance abuse are impulsivity/disinhibition and neuroticism/ negative affectivity, whereas the significance of other personality characteristics such as extraversion/sociability remains inconclusive. ${ }^{19}$ Clinical samples of substance abusers has shown often tension and negative emotions and an inability to cope with the pressures and stress positions. In addition to the deal with the pressures associated with positive relapse of narcotic drugs. ${ }^{20}$ This may explain from the standpoint of the researchers on the negative, reliability and an inability to cope with the pressures of life may be one of a factor of relationship with relapses. The doctor Silk worth in 1930 first talked about the idea of chronic relapse of addiction, where he saw that the cause of the addiction relapses for an individual has insane thinking regarding alcohol, even when sober, feels emotionally and spiritually uncomfortable without the ease and comfort of alcohol. The only way to stop the cycle of relapse, then, is to have a psychic change through a spiritual experience.

Also Carl Jung, founder of analytical psychology also developed a theory of the addiction relapses, where Jung pointed out that the addiction relapse caused by the void for God. Spirituality is the only way to combat alcoholism, Jung believed, and a "vital spiritual experience" is absolutely necessary for a chronic relapse to get and stay sober. Jung also noted that the sheer emotional displacement and rearrange ideas, emotions and attitudes which were once the guiding forces of the lives of these men are suddenly cast to one side, and a completely new set of conceptions and motives begin to dominate them." Silk worth and Jung believed that the efforts in the treatment of addiction relapses are failed efforts, and that the best solution to prevent relapses in alcoholics is to rebuild the spiritual strength. This is what is referred to a Robinson et al. 2011 study that the changes in the spiritual values of a six-month lead to positive results in the treatment of alcohol addiction. ${ }^{21}$ According to ${ }^{22}$ Unconscious fantasies play a determining role in persisting patterns of substance abuse and addiction. Within this context, addiction is understood both as a derivative of the persistence of these unresolved fantasies and an inadequate compromise formation. Also, relapse is a manifestation of the episodic reassertion and the influence of these powerful fantasies. Consequently, successful treatment requires the working through of the underlying fantasy process and the establishment of healthier compromise formations.

\section{Personality disorders}

Generally considered personality disorders or a PD of psychological diseases in which the individual and his emotions and his thoughts, behavior significantly different from the social and cultural norms in society are different, and personality disorders can cause some serious problems, both to the personal level or professional level. Personality disorders are identified through a chronic pattern of behavior or feelings that are difficult to change, because who suffer from personality disorders have a view of life in different from than ordinary look in addition to the difficulty of adapting to the conditions of society. As a result, they dearly in the pattern of living with anxiety, depression, substance abuse and violent behavior, isolation and suicide attempts. The ICD-10 (World Health Organization 1992) defines a personality disorder as: a severe disturbance in the character logical condition and behavioral tendencies of the individual, usually involving several areas of the personality and nearly always associated with considerable personal and social disruption. ${ }^{23}$

But in the Diagnostic and Statistical Manual of Mental Disorders, (DSM-5) the new contains some changes associated personality disorders which were coded on Axis II in DSM-IV. According to the American Society of Psychiatry (APA) the publisher of the DSM5 , the main change in the personality disorders no longer classified according to the second axis, because DSM-5 has done away with the duplicative and confusing nature of "axes" for diagnostic coding. The new system in DSM-5 combines the first three themes contained in previous editions of DSM in one axis, with all mental and other medical diagnoses, according to APA it means the advantage of clinical practice and use the search to remove the artificial differences. ${ }^{24}$ On the other side, we find criticism of categorical diagnosis of personality disorders for DSM-5, because the personality is a continuous process and multi-faceted dimensional, for example, let's consider grandiosity, a characteristic trait of Narcissistic PD. Where is the line of demarcation between health and disorder on the continuum from healthy self-esteem, to selfishness, to self-centered entitlement? How do we decide this? Are there differences across cultures and genders that should be taken into account? Trying to use a categorical approach with a continuous dimension like grandiosity is similar to trying to fit a square peg in a round hole. The numerous problems with our current categorical method of diagnosis are evidence of this poor fit. In addition to the lack of empirical support and the non-specificity of diagnostic criteria, making accurate diagnosis very difficult. ${ }^{25}$ As for the relationship between personality disorders and substance abuse, it 
has indicated many of the previous studies have indicated a relationship between some of personality disorders and substance abuse. The role of personality in the development and course of substance abuse disorders has been debated for many years. The earliest edition of the diagnostic and Statistical Manual of Mental Disorders (APA, 1952) classified alcohol and drug addiction as variations of a sociopathic personality disturbance. The second edition of the diagnostic and Statistical Manual (APA, 1968) Continued classification of substance as a distinct category of personality disorders, but a focus on character weakness or pathology as the basis for addictions was maintained. In the third edition in (APA1980) was the removal of substance abuse classification of the personality disorder. No end interoperability diagnosis completely between personality disorders and substance abuse disorder, because the behaviors associated with the substance use can be used to meet the diagnostic criteria antisocial personality disorder and borderline personality disorder. ${ }^{26}$ Many studies showed the relationship between some personality disorders and substance abuse, for example, according to (Alterman et al study 1997) the antisocial personality disorder (APD) related to substance abuse. There is also a relationship between borderline personality disorder (BPD) and substance abuse, because the major personality factors and their relevance to three models of alcoholism etiology: pharmacological vulnerability, affect regulation, and deviance proneness. These models highlights the interplay between factors that appear to be associated with and to give rise to both BPD. ${ }^{27}$

\section{Study issues}

Because of the importance role of psychological and personal factors, previous studies did not clarify the role of all personality disorders in substance abuse, but was limited to some personality disorders in relation to Substance Abuse Researchers believe that importance of studying the relationship between personality disorders with substance abuse relapses (Paranoid personality disorder Schizoi personality disorder, schizotypal personality disorder, antisocial personality disorder, borderline personality disorder, histrionic personality disorder, narcissistic personality disorder avoidant personality disorder, dependent personality disorder, and obsessive compulsive personality disorder). Especially in the lack of psychological studies on the relationship between substance abuse relapses and personality disorders.

Accordingly, this study aimed to explore the relationship between the personality disorders and substance abuse relapses. The research inquiries are:

i. What is the relationship between personality disorders and substance abuse relapses?

ii. Can substance abuse relapses be predicted by personality disorders?

\section{Operational definition of the variables}

\section{Relapses}

Relapses are intended in the current research is the individua resumption to substance abuse after a month-long recess, it is measured operationally by the respondent's degree through a number of relapses in which the person came back on the substance abuse.

\section{Personality disorders}

Personality disorders are associated with ways of thinking and feeling about oneself and others that significantly and adversely affect how an individual functions in many aspects of life. They fall within
10 distinct types: paranoid personality disorder, schizoid personality disorder, schizotypal personality disorder, antisocial personality disorder, borderline personality disorder, histrionic personality, narcissistic personality disorder, avoidant personality disorder, dependent personality disorder and obsessive-compulsive personality disorder (APA2003). It is measured operationally by the respondent's degree on the personality disorders scale used in this study.

\section{Methodology and procedures}

\section{Methodology}

Descriptive method is used. It enables the researcher to explore the relationship between personality disorders and substance abuse relapses, and examine the predicted relationship to substance abuse relapses through personality disorders.

\section{Study population and sample}

The study tools were applied on 75 substance abuse patient Which is treated in the Eldemer dash Center for Addiction Treatment Under the supervision of the Egyptian Ministry of Health at Arab Republic of Egypt.

\section{Study tools}

The authors developed scale of personality disorders (PRPD), It contains 10 subscales, and standardized on study sample, standardization results was (Table 1A-1J).

There is a positive statistical significance relation between personality disorders(Antisocial personality disorder(ASPDBorderline personality disorder (BPD) Dependent personality disorder (DPD)- Avoidant personality disorder (AVPD)and substance abuse relapses at 0.01. And the results showed no statistically significant relationship between personality disorders(Paranoid personality disorder(PDD)- Schizoid personality disorder(SPD)Schizotypal personality disorder (STPD)- Histrionic personality disorder(HPD)- Narsistic personality disorder(NPD)- ObsessiveCompulsive personality disorder (OCPD) and substance abuse relapses. On the relationship between Antisocial personality disorder and substance abuse relapses. There may be several reasons for that relationship and that may have them substance abuse relapses help the patient to increase the intensity of anti-society, and by increasing boldness toward doing some antisocial behaviors. ${ }^{28}$ In addition to the researchers believe that Patients with antisocial personality disorder also features that they are unable to form emotional relationships or social, making it exposed often to the relapses to substance abuse of the internal sense of material failure in social relationships or to imagine that the society does not deserve love or respect (Table 2).

Furthermore, individuals with ASPD are often excluded from substance abuse treatment programs due to the symptoms of their personality disorder. Likewise individuals with a substance use disorder are often excluded from personality pathology treatment because they are often disruptive and uncooperative ${ }^{29}$ the researchers believe that relationship Antisocial personality disorder(ASPD-linked for the abused substance relapses for several reasons, including that the patient is fully aware that the treatment team are from the community, which shows a lot of animosity and hatred which have interest in the treatment is low and thus show the patient's desire to return to substance abuse. As for the relationship between Borderline personality disorder (BPD and substance abuse relapses the researchers believe that the main feature of this disorder is a pattern of fluctuating mood swings and a distorted self-image and relationships with people. The patient suffers from the difficulty of controlling his 
emotions .. and can cause anger, and dash and volatile temperament repeated to others after him, even if he wanted to establish romantic relationships .In addition to impulsive behavior in patients with borderline personality disorder shows, it can also come from infected personal behavior disorder marginal Impulsivity The abandonment of work or relationships, or to escape. ${ }^{30}$

Table IA PDD: Paranoid personality Disorder

\begin{tabular}{llll}
$\mathbf{N}$ & Item & $\mathbf{R}$ & Sig. \\
\hline I & I think most of people are taking advantage of me for their benefit. & 0.385 & $\mathrm{P}<.0$ I \\
2 & Most of people around me show me their love. However they hate me. & 0.412 & $\mathrm{P}<.0$ I \\
3 & I avoid talking about my private stuff with others, for they will take advantage of this information against me. & 0.388 & $\mathrm{P}<.0$ I \\
4 & Mostly, I know what is behind the words especially, if it was offensive to me. & 0.523 & $\mathrm{P}<.0$ I \\
5 & I always remember the insult no matter how long. & 0.386 & $\mathrm{P}<.0$ I \\
6 & People feel strange about my reaction, because they don't perceive what I mean. & 0.561 & $\mathrm{P}<.0$ I \\
7 & I assume that loyal friends don't exist anymore in the meanwhile. & $0.39 \mid$ & $\mathrm{P}<.01$ \\
\hline
\end{tabular}

A-Item consistency

B- Alpha coefficient was (0.7I).

Table IB SPD: Schizoid personality Disorder

\begin{tabular}{llll}
$\mathbf{N}$ & Item & $\mathbf{R}$ & Sig. \\
\hline 8 & I like to work solo without others help. & 0.569 & $\mathrm{P}<.0$ I \\
9 & I prefer to stay away from family relations. & 0.412 & $\mathrm{P}<.0$ I \\
10 & I'm not interested into having a relation with other sex. & 0.536 & $\mathrm{P}<.0$ I \\
II & The activities which entertain me are few. & 0.479 & $\mathrm{P}<.0$ I \\
I2 & I lack close friends. & 0.0389 & $\mathrm{P}<.0$ I \\
I3 & I care for others praise or criticize for me. & 0.547 & $\mathrm{P}<.0$ I \\
I4 & I think, I'm a quiet person, that is what makes others believe I have superficial emotions. & 0.463 & $\mathrm{P}<.01$ \\
\hline
\end{tabular}

A-Item consistency

B- Alpha coefficient was (0.68).

Table IC STPD: Schizotypal Personality Disorder

\begin{tabular}{llll}
$\mathbf{N}$ & Item & $\mathbf{R}$ & Sig. \\
\hline 15 & When I listen to others talking about an unknown person, I guess that means me. & 0.388 & $\mathrm{P}<.0$ I \\
16 & I believe I have the sixth sense. & 0.397 & $\mathrm{P}<.0$ I \\
17 & Sometimes, I feel that my body has something strange inside, that's annoying me. & 0.412 & $\mathrm{P}<.0$ I \\
18 & I like to talk in a vague way, that only smart people understand me. & 0.387 & $\mathrm{P}<.0$ I \\
19 & I'm always doubt in others. & $0.4 I I$ & $\mathrm{P}<.0$ I \\
20 & I believe I have weak emotions. & 0.453 & $\mathrm{P}<.0$ I \\
21 & Usually, it seems like I have different appearance than others. & 0.395 & $\mathrm{P}<.0$ I \\
22 & I'm lacking friends. & 0.453 & $\mathrm{P}<.01$ \\
\hline
\end{tabular}

A-Itemconsistency

B- Alpha coefficient was (0.74).

Table ID ASPD:Antisocial Personality Disorder

\begin{tabular}{llll}
\hline $\mathbf{N}$ & Item & $\mathbf{R}$ & Sig. \\
\hline 24 & I do whatever I like even if these actions are illegal. & 0.63 I & $\mathrm{P}<.0$ I \\
25 & I enjoy lying and deception others. & 0.593 & $\mathrm{P}<.0$ I \\
26 & I'm an impulsive person. & 0.642 & $\mathrm{P}<.0$ I \\
27 & I always has hassles with others. & 0.58 I & $\mathrm{P}<.0$ I \\
28 & I like the kind of risk that some people describe recklessness. & 0.612 & $\mathrm{P}<.0$ I \\
29 & I can't afford my personal commitments. & 0.63 I & $\mathrm{P}<.0$ I \\
30 & I avoid feeling regret for offending others. & 0.578 & $\mathrm{P}<.01$ \\
\hline
\end{tabular}

A-Itemconsistency

B- Alpha coefficient was (0.81).

Table IE BPD: Borderline personality disorder

\begin{tabular}{|c|c|c|c|}
\hline $\mathbf{N}$ & Item & $\mathbf{R}$ & Sig. \\
\hline 31 & I avoid that people will abandon me. & 0.456 & $\mathrm{P}<.0 \mathrm{I}$ \\
\hline 32 & There were a lot of people whom used to be a role model for me. But now they are not worthy. & 0.398 & $\mathrm{p}<.0 \mathrm{I}$ \\
\hline 33 & My personal idea about my character is not clear, which make me unconfident with my business and relations. & 0.541 & $\mathrm{P}<.0 \mathrm{I}$ \\
\hline 34 & I think I'm an impulsive person. & 0.389 & $\mathrm{P}<.0 \mathrm{I}$ \\
\hline 35 & Sometimes I injure myself physically, that may reach a suicide. & 0.542 & $\mathrm{P}<.0 \mathrm{I}$ \\
\hline 36 & I'm a moody person. & 0.439 & $\mathrm{P}<.0 \mathrm{I}$ \\
\hline 37 & I always feel emptiness. & 0.479 & $p<.01$ \\
\hline
\end{tabular}

Citation: Gaber OH,Abelfatah ME. Relationship between personality disorders and relapses among sample of substance abuse patients.J Psychol Clin Psychiatry. 2016;6(6): I I-12. DOI: I0.15406/jpcpy.2016.06.0038 | 
Table Continued..

\begin{tabular}{lll}
\hline $\mathbf{N}$ & Item & Sig. \\
\hline 38 & I find it hard to control my anger. & R \\
39 & Sometimes I feel like a smart aleck. & $0.5 I 3$ \\
\hline
\end{tabular}

A-Itemconsistency

B- Alpha coefficient was (0.76).

Table IF HPD: Histrionic personality disorder

\begin{tabular}{|c|c|c|c|}
\hline $\mathbf{N}$ & Item & $\mathbf{R}$ & Sig. \\
\hline 40 & I get annoyed in many situations, which I'm not the main axis to the others. & 0.394 & $\mathrm{P}<.01$ \\
\hline 41 & I like to attract the other sex to me in a sexual way. & 0.421 & $\mathrm{P}<.0 \mathrm{I}$ \\
\hline 42 & I believe that others think I'm superficial emotionally. & 0.386 & $\mathrm{P}<.01$ \\
\hline 43 & I like to grab others attention with my external appearance. & 0.425 & $\mathrm{P}<.0 \mathrm{I}$ \\
\hline 44 & $\begin{array}{l}\text { When I'm expressing myself, I don't mention the details, because my expressions are enough for them to } \\
\text { understand what I mean. }\end{array}$ & 0.473 & $\mathrm{P}<.0 \mathrm{I}$ \\
\hline 45 & I like to express my feelings strongly, which make others think I'm acting. & 0.391 & $\mathrm{P}<.0 \mathrm{I}$ \\
\hline 46 & I'm easily affected by others. & 0.442 & $\mathrm{P}<.0 \mathrm{I}$ \\
\hline 47 & Although, I have intimate relationship with the others but I have a few friend. & 0.396 & $\mathrm{p}<.01$ \\
\hline
\end{tabular}

A-Itemconsistency

B- Alpha coefficient was (0.8I).

Table IG NPD: Narsistic Personality Disorder

\begin{tabular}{|c|c|c|c|}
\hline $\mathbf{N}$ & Item & $\mathbf{R}$ & Sig. \\
\hline 48 & Although, I have few achievements, but I like to be recognized as successful person. & 0.435 & $\mathrm{p}<.0 \mathrm{l}$ \\
\hline 49 & I have a lot in a daydream, where I see myself as someone brilliant. & 0.557 & $\mathrm{p}<.01$ \\
\hline 50 & I should only befriended by gorgeous people & 0.425 & $\mathrm{p}<.01$ \\
\hline 51 & I think that others should praise me than any other person, because my actions are distinctive. & 0.396 & $\mathrm{p}<.01$ \\
\hline 52 & I feel that, I deserve more better case than I'm in now. & 0.513 & $\mathrm{p}<.01$ \\
\hline 53 & I establish friendly relations with the people who I only benefit from. & 0.461 & $\mathrm{p}<.01$ \\
\hline 54 & I refuse to get emotionally affected and share feelings with others. & 0.436 & $\mathrm{p}<.01$ \\
\hline 55 & I believe that, a lot of people reached achievements that they don't deserve it. & 0.456 & $\mathrm{p}<.01$ \\
\hline 56 & In many situations, people think I am a bumptious person. & 0.462 & $p<.01$ \\
\hline
\end{tabular}

A-Itemconsistency

B- Alpha coefficient was (0.76).

Table I H AVPD:Avoidant Personality Disorder

\begin{tabular}{|c|c|c|c|}
\hline $\mathbf{N}$ & Item & $\mathbf{R}$ & Sig. \\
\hline 57 & I avoid any team work that request working with others. & $0.47 I$ & $\mathrm{p}<.0 \mathrm{l}$ \\
\hline 58 & I refuse engaging with people unless I'm sure they love me. & 0.539 & $\mathrm{P}<.01$ \\
\hline 59 & I avoid intimate relations, as I afraid of becoming a laughingstock. & 0.479 & $\mathrm{P}<.0 \mathrm{I}$ \\
\hline 60 & I'm so worried of what will be said about me in social situations. & 0.531 & $\mathrm{P}<.0 \mathrm{l}$ \\
\hline 61 & I'm afraid to deal in new social situations because I believe I am unable to communicate with others. & 0.442 & $\mathrm{P}<.01$ \\
\hline 62 & I lose the personal attractiveness. & 0.526 & $\mathrm{P}<.0 \mathrm{l}$ \\
\hline 63 & I prefer not to risk in any new social activity in which I will show a great deal of shame and confusion. & 0.399 & $\mathrm{p}<.01$ \\
\hline
\end{tabular}

A-Itemconsistency

B- Alpha coefficient was (0.67).

Table II DPD: Dependent Personality Disorder

\begin{tabular}{|c|c|c|c|}
\hline $\mathbf{N}$ & Item & $\mathbf{R}$ & Sig. \\
\hline 57 & I avoid any team work that request working with others. & 0.471 & $\mathrm{P}<.01$ \\
\hline 58 & I refuse engaging with people unless I'm sure they love me. & 0.539 & $\mathrm{P}<.01$ \\
\hline 59 & I avoid intimate relations, as I afraid of becoming a laughingstock. & 0.479 & $\mathrm{P}<.01$ \\
\hline 60 & I'm so worried of what will be said about me in social situations. & 0.531 & $\mathrm{P}<.0 \mathrm{I}$ \\
\hline 61 & I'm afraid to deal in new social situations because I believe I am unable to communicate with others. & 0.442 & $\mathrm{P}<.01$ \\
\hline 62 & I lose the personal attractiveness. & 0.526 & $\mathrm{P}<.01$ \\
\hline 63 & I prefer not to risk in any new social activity in which I will show a great deal of shame and confusion. & 0.399 & $\mathrm{P}<.0 \mathrm{I}$ \\
\hline
\end{tabular}

A-Itemconsistency

B- Alpha coefficient was (0.83).

Citation: Gaber OH,Abelfatah ME. Relationship between personality disorders and relapses among sample of substance abuse patients.J Psychol Clin Psychiatry. 2016;6(6): I I-I2. DOI: 10.15406/jpcpy.2016.06.0038। 
Table IJ OCPD: Obsessive-Compulsive Personality Disorder

\begin{tabular}{llll}
\hline $\mathbf{N}$ & Item & $\mathbf{R}$ & Sig. \\
\hline 7 I & I always get busy with rules, regulations and organizing work to the extent that I may lose focus on the main issue. & 0.485 & $\mathrm{P}<.0$ I \\
72 & I aim for perfectionism in my work, that's why I failed to finish and Complete many work duties. & 0.562 & $\mathrm{P}<.0$ I \\
73 & I devote myself wholeheartedly to work to the extent that I may forsake my friendships and leisure time. & 0.487 & $\mathrm{P}<.0$ I \\
74 & I am sticking to the moral values to the degree of severity. & 0.532 & $\mathrm{P}<.0$ I \\
75 & I prefer to keep old stuff and I really don't forsake it even if I didn't need it anymore. & 0.49 I & $\mathrm{P}<.0$ I \\
76 & I rarely delegate any work to anybody unless he will follow my way to get the work done. & 0.56 I & $\mathrm{P}<.0$ I \\
77 & I consider myself a carful person with spending money, as I save it to the insurable future. & 0.497 & $\mathrm{P}<.0$ I \\
78 & I'm a stubborn person. & 0.553 & $\mathrm{P}<.0$ I \\
\hline
\end{tabular}

A-Itemconsistency

B- Alpha coefficient was (0.74).

Table 2 Correlation coefficient and statistical significance between personality disorders and substance abuse relapses

\begin{tabular}{lll}
\hline Variables & Substance Abuse Relapses & Significance \\
\hline Paranoid personality disorder(PDD) & 0.17 & $\mathrm{P}>.05$ \\
\hline Schizoid personality disorder(SPD) & 0.19 & $\mathrm{P}>.05$ \\
\hline Schizotypal personality disorder (STPD) & 0.1 & $\mathrm{P}>.05$ \\
\hline Antisocial personality disorder(ASPD) & 0.43 & $\mathrm{P}<.01$ \\
\hline -Borderline personality disorder (BPD) & 0.48 & $\mathrm{P}<.01$ \\
\hline Histrionic personality disorder(HPD) & 0.15 & $\mathrm{P}>.05$ \\
\hline Narsistic personality disorder(NPD) & 0.18 & $\mathrm{P}>.05$ \\
\hline Avoidant personality disorder (AVPD) & 0.42 & $\mathrm{P}<.01$ \\
\hline Dependent personality disorder (DPD) & 0.54 & $\mathrm{P}<.01$ \\
\hline Obsessive-Compulsive personality disorder (OCPD) & 0.11 & $\mathrm{P}>.05$ \\
\hline
\end{tabular}

Table 3 Indicates that dependent personality Disorder(DPD) and Border line personality disorder(BPD)

\begin{tabular}{|c|c|c|c|c|c|}
\hline Model I & \multicolumn{2}{|c|}{ Unstandardized Coefficients } & \multirow{2}{*}{$\begin{array}{l}\text { Standardized Coefficients } \\
\text { Beta }\end{array}$} & \multirow[t]{2}{*}{$\mathbf{t}$} & \multirow[t]{2}{*}{ Sig. } \\
\hline & B & Std. Error & & & \\
\hline Constant & 2.652 & 0.622 & & 4.267 & $P<0.000$ \\
\hline DPD & 0.493 & 0.134 & 0.395 & 3.675 & $p<0.000$ \\
\hline
\end{tabular}

Table 4 Indicates that dependent personality Disorder(DPD) and Border line personality disorder(BPD) predict relapse

\begin{tabular}{|c|c|c|c|c|c|}
\hline \multirow[t]{2}{*}{ Model 2} & & & Standardized Coefficients & \multirow[t]{2}{*}{$\mathbf{t}$} & \multirow[t]{2}{*}{ Sig. } \\
\hline & \multicolumn{3}{|c|}{ Unstandardized Coefficients } & & \\
\hline & B & Std. Error & Beta & & \\
\hline Constant & 2.496 & 0.686 & & 3.64 & $p<0.01$ \\
\hline DPD & 0.551 & 0.114 & 0.441 & 4.848 & $\mathrm{P}<0.000$ \\
\hline BPD & 0.273 & 0.081 & 0.299 & 3.368 & $\mathrm{p}<0.01$ \\
\hline
\end{tabular}

Table 5 Indicates that dependent personality Disorder(DPD) Border line personality disorder(BPD)

\begin{tabular}{llllll}
\hline Model 3 & \multicolumn{2}{l}{ Un standardized Coefficients } & Standardized Coefficients & t & Sig. \\
\hline & B & Std. Error & Beta & & \\
Constant & I.648 & 0.788 & - & 2.091 & $\mathrm{P}<0.040$ \\
DPD & 0.488 & 0.115 & 0.392 & 4.24 & $\mathrm{P}<0.000$ \\
BPD & 0.336 & 0.085 & 0.369 & 3.951 & $\mathrm{P}<0.000$ \\
ASPD & 0.155 & 0.076 & 0.2 & 2.047 & $\mathrm{P}<0.044$ \\
\hline
\end{tabular}

\section{Results and Discussion}

\section{The first inquiry}

What is the relationship between personality disorders and substance abuse relapses?

There is a possibility that the relationship between borderline personality disorder and substance abuse relapses is that patients with borderline personality disorder suffer from the problem of the loss of the ability to regulate emotion which leads to the failure of self-control and they have to suffer continuously from the setback to the use of narcotic substances. The incorporation of DBT emotion regulation and distress tolerance skills in particular may be especially useful in targeting dropout within borderline personality disorder. Indeed, the focus of these skills on controlling behaviors and acting effectively in the context of emotional distress would likely have direct relevance to reducing treatment dropout among male SUD patients with BPD. The integration of such protocols into standard residential substance abuse treatment may enhance treatment retention rates for patients at risk for leaving treatment prematurely. ${ }^{31}$ Individuals with dependent personality disorder have great difficulty making everyday decisions, And such people do not feel able to dependent on themselves in most of their lives, whether living with their parents and live married life, The loss of the ability to withstand stressful situations because they're 
not used to cope with stressful situations by themselves but always dependent on others.

The researchers believe that the symptoms of dependent personality disorders working on the patient who is suffering from substance abuse relapse has continuously believed that those materials to help him cope with life, especially that he has always loved that there is nothing supporting him helps him to cope with stressful life situations. In addition to that dependent personality disorder patients are aware of the reliability of relapse to substance abuse as a narcotic used as defense mechanisms to escape from the frustrating situations coping. Resort People with dependent personality disorder to retire from public life and face the stress of living and the difficulties and crises to rely on the house and trying to take cover under the shade of a wife or acting on behalf of the mother, or its replacement, so he prefers to stay within the confines of the narrow life to avoid stress or exposure to the face that lead to further deterioration its ability to cope with the crises of life after it weakened his ability to durability and its ability to cope and that it not be a easy when bad eggs people in the light of life that need to confrontation and the struggle and the challenge of difficulties circumstances and when it fails at any find any support him dependent continue to relapse process to substance abuse as a kind of the types of support that are believed to help him to cope the problem of life. ${ }^{32}$

\section{The second inquiry}

Can substance abuse relapses be predicted by personality disorders?

Independent Variable $($ Replace $)=2.652+\{0.493 *$ Independent Variable (Dependent Personality Disorder) $\}$.

Table 3 indicates that dependent personality Disorder (DPD) predicts relapse among substance abuse patient, when (DPD) patient remit from substance abuse he may feel lonely and lack of fellow group, he need for the person to be taken care of and a fear of being abandoned or separated from important individuals in his life. he depends on others for everything and afraid that the others go away from him This is due to the lack of his personal efficiency and low self-esteem. In this case maybe cause to relapse, He will have get psychological satisfaction from relapse to narcotics.

Independent Variable $($ Replace $)=2.496+\{0.551 *$ Independent Variable 1. Dependent Personality Disorder $+0.273 *$ Independent Variable 2. borderline personality disorder\}.

Independent Variable $($ Replace $)=1.648+\{0.488 *$ Independent Variable 1. Dependent Personality Disorder $+0.336^{*}$ Independent Variable 2. borderline personality disorder+ $0.155^{*}$ Independent Variable 3.antisocial personality disorder $\}$.

Table 4 indicates that dependent personality Disorder(DPD) and Border line personality disorder(BPD) predict relapse, this comorbidity maybe cause relapse because it influence on substance abuse patient to minimize his severe mood by Depending on the narcotics. Also Patient deal with leisure feelings by return to addiction, he is impulsivity to any relationships that help him to feel he is not alone, so patient always prefer to go with addiction group and take narcotics.

Table 5 indicates that dependent personality Disorder (DPD) Border line personality disorder (BPD) predict relapse, and antisocial personality disorder (APD) predict relapse, common symptom in(BPD) and (APD) is impulsivity, in rehabilitation substance abuse patient and remission if he cannot reduce impulsivity and (DPD) symptoms maybe relapse and return to take narcotics, Moreover antisocial personality disorder patient cannot properly estimate the consequences that cause to relapse..$^{33}$

\section{Conclusions}

This study provided several initial findings regarding factors that may predict relapse, the results indicate that dependent personality Disorder (DPD) as predictor to relapse, and it with Border line personality disorder (BPD) together predict relapse, also antisocial personality disorder (APD) with them predict relapse among substance abuse patient, so when patient in rehabilitation we should remit personality disorders particularly dependent, Border line ,and antisocial personality disorder. This remission maybe reduce substance abuse relapse.

\section{Acknowledgments}

None.

\section{Conflicts of interest}

Author declares there are no conflicts of interest.

\section{Funding}

None.

\section{References}

1. Mukherjee A, Manna N, Sanyal S. Socio demographic and substance use correlates of repeated relapse among patients presenting for relapse treatment at an addiction treatment center in Kolkata, India. Afr Health Sci. 2013;13(3):791-799.

2. Tims F, Leukefeld C. Relapse and Recovery in Drug Abuse, research analysis system and utilization, US Government Printing Office, Washington DC, USA. 1986.

3. Fiorentene R. After Treatment: Are 12-Steps Programs Effective in Maintaining Abstinence? Am J Drug Alcohol Abuse. 1999;25(1):93-116.

4. Manejwals O. How Often Do Long-Term Sober Alcoholics and Addicts Relapse?" Psychology Today. 2014.

5. Xie H , Mchugo, G, Fox M , et al. Special Section on Relapse Prevention: Substance Abuse Relapse in a Ten-Year Prospective Followup of Clients With Mental and Substance Use Disorders ,Psychiatric services. 2005;56(10):1282-1287.

6. Elmohndy K. Drug psychological, social and economic impact in the countries of the Cooperation Council for the Arab Gulf States. Criminal information center for combating drug Cooperation Council for the Arab States of the Gulf, Qatar, Doha. 2013.

7. Nosera E. Drug addiction in Algerian society, addict between the disease and criminality. Journal of Social Studies and Research - Valley University. 2013.

8. Samir S. Addiction theories. 2016

9. Hendin H. Psychosocial Theory of Drug Abuse - A Psychodynamic Approach. NIDA Res Monogr. 2016;30:195-200.

10. Elmaghraby S. The phenomenon of Cannabis abuse, psycho-social study, knowledge publishing house, Cairo, Egypt. 1963

11. Abdelsalam F. The psychology of addiction, the world of books for publication. (1st edn), Cairo, Egypt. 1977.

12. Abdelhamed A. Addiction and alienation, the differences between the volunteers of heroin addicts in the sense of alienation from self and others, a study using clinical testing. Knowledge Dar University, Alexandria, Egypt. 1993 
13. Horvath T, Misra A, Epner A Cooper G. Social Learning Theory Of Addiction And Recovery Implications. 2016.

14. American Psychiatric Association. Highlights of Changes from DSMIV-TR to DSM-5. American psychiatric publishing. 2013.

15. Hendershot C, Witkiewitz K, George W, et al. Relapse prevention for addictive behaviors. Subst Abuse Treat Prev Policy. 2011;6:17.

16. White W, Ali S . Lapse and relapse: Is it time for a new language. 2010.

17. Ramo D, Brown S. Classes of substance abuse relapse situations: A comparison of adolescents and adults. Psychol Addict Behav. 2011;22(3):372-379.

18. Abdelaziz N. Study of relapse of substance abusers in an Egyptian sample. Unpublished master, faculty of medicine, Benha University, Egypt. 2012.

19. Mellos E, Liappas I, Paparrigopulos T. Comorbidity of Personality Disorders with Alcohol Abuse. In Vivo. 2016;24(5):761-769.

20. Sinha R. How does stress increase risk of drug abuse and relapse? Psychopharmacology (Berl). 2001;158(4):343-359.

21. Smith HV. Back to basics to prevent relapse. 2013.

22. Cattano J. The influence of unconscious fantasy process in addictions and relapse. Journal of clinical social work. 1996;24(4):429-442.

23. Kendell RE. The distinction between personality disorder and mental illness, The British Journal of Psychiatry Feb. 2002;180 (2):110-115.

24. Grohol J. DSM-5 Changes: Personality Disorders (Axis II). Psych central professional. 2013.
25. Zupanick CE. The New DSM-5: Personality Disorder. 2016.

26. Kim T Mueser, Robert E Drake, Theimann H Ackerson, et al. Antisocial Personality Disorder, Conduct Disorder,and Substance Abuse in Schizophrenia. J Abnorm Psychol. 1997;106(3):473-477.

27. Timothy J, Kenneth J, Minks C, et al. Borderline personality disorder and substance use disorders - a review and integration. Clin Psychol Rev. 2000;20(2):235-253.

28. Bahlmann M, Preuss UW, Soyka M. Chronological Relationship between Antisocial Personality Disorder and Alcohol Dependence. Euorbean addiction research. 2002.

29. Haase, Joleen M. Co-occuring Antisocial Personality Disorder and Substance Use Disorder: Treatment Interventions. Graduate Journal of Counseling Psychology. 2009;1(2).

30. Shari M. Loving Someone with Borderline Personality Disorder. The Guilford Press. 2011.

31. Tull M, Gratz K. The Impact of Borderline Personality Disorder on Residential Substance Abuse Treatment Dropout among Men, drug and alcohol dependence. Drug Alcohol Depend. 2013;121(1-2):97-102.

32. Amarh A. Dependent personality. Civilized dialogue. 2005;1176.

33. Thomas V. Pesonality disorders and substance abuse-patterns of comorbidity in an inpatient treatment population. PHD in Texas Tech University. 1995. 